\title{
EDITORIAL
}

\section{Disparities in Maternal Healthcare Services}

\section{Abraham Haileamlak, MD, Professor of Pediatrics and Child Health}

It is an established fact that better care to pregnant and laboring mothers improves the health of both the mother and the newborn. Skilled care during pregnancy, childbirth, and the postpartum period are important interventions in reducing maternal and neonatal morbidity and mortality. Taking this fact into consideration, many countries gave priority to improving maternal health. As a result, there has been impressive progress in reducing maternal mortality and morbidity worldwide with substantial achievement in sub-Saharan Africa. However, there are big disparities in maternal health indicators among countries and among regions with in countries.

The recent national survey in Ethiopia showed similar improvement in maternal health indicators. Antenatal care coverage by skilled health personnel increased from 34\% in 2011 to $74 \%$ in 2019 , birth in health facility increased from $10 \%$ in 2011 to $48 \%$ in 2019 and postnatal care increases to $34 \%$ in 2019 .

Notwithstanding this impressive achievement at national level, some regional states are lagging far behind. Among the regional states which are lagging behind in maternal healthcare services is Somali region where only $30 \%$ of pregnant women received antenatal care, $26 \%$ of delivering mothers were attended by skilled personnel and 10\% had postnatal check (1).

International organizations and respective ministries of health need to work hand-in-hand to narrow the wide disparities in maternal healthcare services among countries and regional states.

The current issue of the journal, the second regular issue for the year 2020, contains an editorial, fourteen original articles, three reviews and a case report focusing on various topics. Three of the original articles and one of the reviews in this issue deal with maternal health.

I invite readers to read through these articles and appreciate or utilize the contents. I also urge readers to forward comments and suggestions to the editor or the corresponding authors.

\section{REFERENCES}

1. Central Statistical Agency (CSA) [Ethiopia] and ICF International. Ethiopia demographic and health survey 2016: key indicators report: Addis Ababa, Ethiopia, and Rockville, Maryland, USA. CSA and ICF. 2016. [Google Scholar] 